\title{
Evaluation of the Performance of PCR and Hybrid Capture 2 in the Detection of Human Papillomavirus Associated with Cervical Cancer in Algeria
}

\author{
Melhag Mohamed ${ }^{1}$, Kerroucha Rabah ${ }^{1,}$, Melouli Hamid ${ }^{2}$, Midoun Nori ${ }^{3}, Z_{\text {Zemour Lakhdar }}^{3}$, \\ Ayyach Ghassan ${ }^{4}$, Asselah Fatima ${ }^{5}$, Bendissari Kheira ${ }^{6}$, EL Kebir Fatima Zohra ${ }^{1}$ \\ ${ }^{1}$ Biology Department, Faculty of Science of Nature and Life, University of Oran 1 Ahmed Ben Bella, Oran, Algeria \\ ${ }^{2}$ Institut Pasteur of Algeria, Algiers, Algeria \\ ${ }^{3}$ Department of Epidemiology and Preventive Medicine, EHU of Oran, Oran, Algeria \\ ${ }^{4}$ Gynecology-Obstetrics Department. EPH of Zeralda, Algiers Algeria \\ ${ }^{5}$ Pathology Department, Mustapha Pasha University Hospital, Algiers, Algeria \\ ${ }^{6}$ Pathology Department, Beni Messous University Hospital, Algiers, Algeria

\section{Email address:} \\ melhagmed@yahoo.fr(M. Mohamed),rkerroucha@yahoo.fr(K. Rabah),hmelouli@yahoo.fr (M. Hamid), \\ semepehuo@gmail.com (M. Nori), lakhdarzemour@gmail.com (Z.Lakhdar),ghassan8845@gmail.com( $\Lambda$. Ghassan), \\ asselahf@hotmail.fr (A. Fatima),kheirabouzidi45@gmail.com (B. Kheira), fzelkebir@yahoo.fr (E. K. F. Zohra) \\ ${ }^{*}$ Corresponding author
}

\section{To cite this article:}

Melhag Mohamed, Kerroucha Rabah, Melouli Hamid, Midoun Nori, Zemour Lakhdar, Ayyach Ghassan, Asselah Fatima, Bendissari Kheira, EL Kebir Fatima Zohra. Evaluation of the Performance of PCR and Hybrid Capture 2 in the Detection of Human Papillomavirus Associated with Cervical Cancer in Algeria. Cancer Research Journal. Vol. 6, No. 3, 2018, pp. 84-91. doi: 10.11648/j.crj.20180603.13

Received: May 28, 2018; Accepted: July 2, 2018; Published: July 27, 2018

\begin{abstract}
To evaluate and compare the performance of PCR (polymerase chain reaction) and second-generation capture hybridization (HC2) in the detection of high-risk Human Papillomavirus (HPV-HR) and to estimate their prevalence among normal cervical, dysplastic and cervical cancer in the Algerian population. 264 women were subjected to cyto-histological and colposcopic diagnostics and to the HPV test by PCR and Hybrid capture 2. The search for HPV DNA by conventional PCR was carried out with MY09 / 11 consensus primers and the typing of HPV with the hybridization technique in solution, Digene Sharp Signal for PCR. Hybrid Capture ${ }^{\circledR} 2$ was performed with the digene HPV HC2 DNA Test kit. The PCR and HC2 performance tests included sensitivity, specificity, positive and negative predictive values, Youden's index, and Yule's Q coefficient. HPV-HR research has shown that these viruses are associated with $100 \%$ high-grade lesions, $88.2 \%$ by PCR and $83.3 \%$ by HC2 $(p=0.8)$ with invasive cancer. The PCR and HC2 performance tests were in favor of HCV HPV testing which was more sensitive, more specific, more predictive and more effective. The results on the prevalence of HPV-HR associated with cervical lesions are comparable to those in the literature. In comparison with PCR, the capture hybridization technique 2 is recommended for HPV diagnosis because of its better performance and simplicity.
\end{abstract}

Keywords: Cervical Cancer, Precancerous Lesions, Prevalence, HPV Testing, PCR, Capture Hybridization 2

\section{Introduction}

With an estimated global prevalence of 2.3 million women, an estimated annual global incidence of 528000 new cases and an estimated 266000 deaths each year, cervical cancer is the world's second largest cancers affecting women [1]. It is preceded for many years by dysplasias that can be detected. Cervical cancer follows the persistence of a virus: the human papillomavirus or HPV that is transmitted through sexual contact [2, 3]. In Algeria, cervical cancer is the second most common cancer in women after breast cancer. 4 women die each day from this cancer and 1600 cases are recorded annually, 80 to $90 \%$ of whom have reached advanced stage of the disease [4]. Cervical cancer is the only cancer that can 
benefit from true prevention. This prevention is carried out by screening for its precursors thanks to the smear test performed on women aged 25 to 65 years old. This screening is carried out today and for more than 40 years and has led to a reduction in the incidence of cervical cancer and its mortality in most rich countries. While smear is now the most common means of detecting pre-cancerous or cancerous lesions, it is limited by limited sensitivity. In developed countries, nearly $30 \%$ of cervical cancers have not been identified.

New screening techniques are emerging that are more sensitive and can further reduce the incidence of cervical cancer. These tests, using molecular biology techniques, propose not to look for the precursors of cervical cancer but directly the presence (or not) of their causative agent: HPV. These tests are beginning to be adopted by some European countries in addition to the smear [5,6]. They make it possible to identify the presence of the virus, even before the appearance of the lesions. If the test is negative, the risk of developing cervical cancer within 5 years is practically nil, if, on the other hand, the HPV test is positive, it is therefore necessary to look for the possible lesion by the smear which can then lead to colposcopy.

There are two main types of techniques that can be used on cervical uterine specimens: liquid phase hybridization techniques and PCR (Polymerase Chain Reaction) techniques. Both of these techniques are intended to detect high-risk papillomavirus (HPV-HR), agents necessary for the development of the cervical tumor. The sensitivity of these tests to detect high-grade lesions likely to progress to invasive cancer would be greater than $95 \%$ for the majority of specialists. This study consists of evaluating and comparing the performance of PCR and second generation capture hybridization (HC2) in the detection of HPV-HR and estimate their prevalence among normal, dysplastic and invasive tumors within a population in the perspective of introducing the HPV molecular test in the diagnosis of cervical cancer, which is based on conventional cytopathology and colposcopy techniques. To do this, it's proceeded by the comparison of the diagnosis of cervix by cyto-histology and colposcopy and the comparison of HPV typing results obtained by PCR and $\mathrm{HC} 2$.

\section{Material and Methods}

\subsection{Biological Material}

264 women from the Algiers region were the subject of this study during the period 2010-2013. These women were subjected to cyto-histology and colposcopy examinations. The samples taken from these women were also the subject of HPV research and typing using two molecular biology techniques: Capture Hybridization 2 (HC2) and PCR. The samples were transported in the transport medium (Digène HPV DNA Assay), they were treated and stored at $-70^{\circ} \mathrm{C}$ for biopsies and at $-20^{\circ} \mathrm{C}$ for swabs / scrapings. The cytohistopathological examination of the samples taken (smears and biopsies) was carried out at the pathology departments of the Mustapha Pacha and Beni Messous UHCs (Algiers). The colposcopy exam was carried out at the Genecology and Obstetrics Department at EPH Zéralda (Algiers). The WHO 2003 [7] classification was adopted for the description of cervical lesions. The samples taken from women, who were the subject of this study, were part of the diagnostic procedure for cervical lesions falling within the remit of the Gynecology and Obstetrics Department of EPH Zéralda (Algiers) and do not fit into any case in a fundamental research.

\subsection{Methods}

\subsubsection{Capture Hybridization: Hybrid Capture ${ }^{\circledR} 2$ (Digen HPV HC2 DNA Test) (QIAGEN)}

Hybrid Capture ${ }^{\circledR} 2$ (HC2) allows the detection of at least one of the 13 types of HPV-HR (16, 18, 31, 33, 35, 39, 45, $51,52,56,58,59$ and 68$)$ and / or at least one of the 5 types of HPV-BR $(6,11,42,43,44)$. It can detect about $1 \mu \mathrm{g}$ of HPV genome per $\mathrm{ml}$, or about 5000 copies / $\mathrm{ml}$. The technique has been applied as previously described [8]. HPV DNA is denatured and then hybridized with HPV-BR or HPV-HR specific RNA probes. The DNA-RNA hybrid thus formed is captured by an antihybrid antibody attached to the bottom of a well of a microplate. The presence of the hybrid is revealed by a secondary anti-hybrid antibody coupled to an alkaline phosphatase molecule. In the presence of HPV DNA, the substrate of the cleaved alkaline phosphatase gives a chemiluminescent molecule which can then be detected and quantified in relative light units (RLU). Positive and negative controls are incorporated into each series.

\subsubsection{The Chain Amplification Reaction (PCR)}

\section{(i) Extraction and Purification of DNA}

The biopsy fractions dedicated to the study of the DNA are cut with sterile slides in lysis buffer (10 mM Tris, $\mathrm{pH} 7.4,50$ mM EDTA, $150 \mathrm{mM} \mathrm{NaCl}, 1 \%$ Sarkosyl ) and treated with RNase A (10 mg / ml) for 2 hours at $37^{\circ} \mathrm{C}$. After digestion with proteinase $\mathrm{K}$, the DNA is extracted by the phenolchloroform method, this DNA is then precipitated with ethanol, and then solubilized in $20 \mu \mathrm{l}$ of TE buffer $(10 \mathrm{mM}$ Tris-HCl, $\mathrm{pH}$ 8.0; mM EDTA).

Scraping is performed by the cytobrush (Cervical Brush, Digene), and then discharged from the cells into the transport medium (STM Digene medium, Qiagen). Nucleic acids are extracted by the phenol chloroform method, in the same way as for biopsies.

\section{(ii) PCR [9]}

It is carried out in a HYBEDTM thermal cycler. For this purpose, biotinylated MY09 / 11 consensus primers which make it possible to amplify the HPV L1 gene have used. The sequences of these primers are as follows:

(1) MY11: 5'-GCMCAGGGWCATAAYAATGG-3'.

(2) MY09: 5'-CGTCCMARRGGAWACTGATC-3'.

The reaction is carried out in a total volume of $25 \mu \mathrm{l}$ containing 0.1 to $1.0 \mathrm{pg}$ of DNA of the sample, $0.4 \mu \mathrm{M}$ of 
each primer, $1.5 \mathrm{mM}$ of $\mathrm{MgCl}_{2}, 200 \mu \mathrm{M}$ of each dNTP. 1X, and $0.5 \mathrm{U}$ PCR buffer from AmpliTaq Gold (Applied Biosystems, Roche). Initial denaturation was carried out at $94^{\circ} \mathrm{C}$ for $10 \mathrm{~min}$, followed by 35 cycles each at $94^{\circ} \mathrm{C}$ for 30 sec, $64^{\circ} \mathrm{C}$ for $30 \mathrm{sec}, 72^{\circ} \mathrm{C}$ for $1 \mathrm{~min}$. A final extension is carried out at $72^{\circ} \mathrm{C}$ for $7 \mathrm{~min}$. This reaction with such primers generates a 450 bp amplicon. High-risk, low-risk HPV was determined by the Digene Sharp Signal TM system for digene hybridization (Digene Diagnostics).

\section{(iii) Agarose Gel Electrophoresis}

A volume of $5 \mu \mathrm{l}$ of each PCR product is mixed with a loading buffer and then subjected to Agarose gel electrophoresis. The concentration of the gel varies, generally from 0.8 to $1.2 \%$ depending on the size of the DNA produced. Ethidium bromide (Sigma) is used to reveal the spots. The migration buffer consists of TAE $1 \mathrm{X}$, prepared from a $50 \mathrm{X}$ concentrated solution $(242 \mathrm{~g}$ Tris, $57.2 \mathrm{ml}$ acetic acid and $100 \mathrm{ml} 0.5 \mathrm{M}$ EDTA for a final volume of 1 liter). Electrophoresis is carried out in a horizontal tank (Biorad). The DNA samples are deposited in the wells using a $1 \mathrm{X}$ loading solution obtained from the $6 \mathrm{X}$ solution $(50 \%$ glycerol, $0.25 \%$ bromophenol blue, $0.25 \%$ xylene cyanol). The migration takes place at 100 volts and the revelation of the DNA is done by autoradiography.

\subsubsection{Statistical Method}

For statistical calculations, the Epidata Analysis software V2.2.3.187 has been used. These statistical calculations concerned the following parameters: sensitivity, specificity, positive predictive values (VPP) and negative values (VPN), Youden's index, Yule's Q coefficient and $\mathrm{p}$ value. Values of $\mathrm{p} \leq 0.05$ are considered statistically significant.

Youden's index measures the diagnostic orientation efficiency of a test. Its diagnostic value is maximum when the index is close to 1 . The Q coefficient of Yule measures the intensity of the link between the two variables (disease / sign). It varies from 0 to 1 . The intensity of the connection is very strong for $\mathrm{Q}$ between 0.7 and 1 .

\section{Results}

\subsection{Distribution of Cases Studied by Age Group}

For the 264 cases studied, $50 \%$ of women are between the ages of 30 and 40, which is the peak age. The lowest percentage $(10.2 \%)$ is in the over 50 age group. (Table 1, Figure 1).

Table 1. Distribution of cases studied by age group.

\begin{tabular}{llllll}
\hline Age group & $<\mathbf{3 0}$ years & $\mathbf{3 0 - 4 0}$ years & $\mathbf{4 1 - 5 0}$ years & $>\mathbf{5 0}$ years & Total \\
\hline Number & 36 & 132 & 69 & 27 & 264 \\
Percentage & 13.6 & 50 & 26.1 & 10.2 & 100 \\
\hline
\end{tabular}

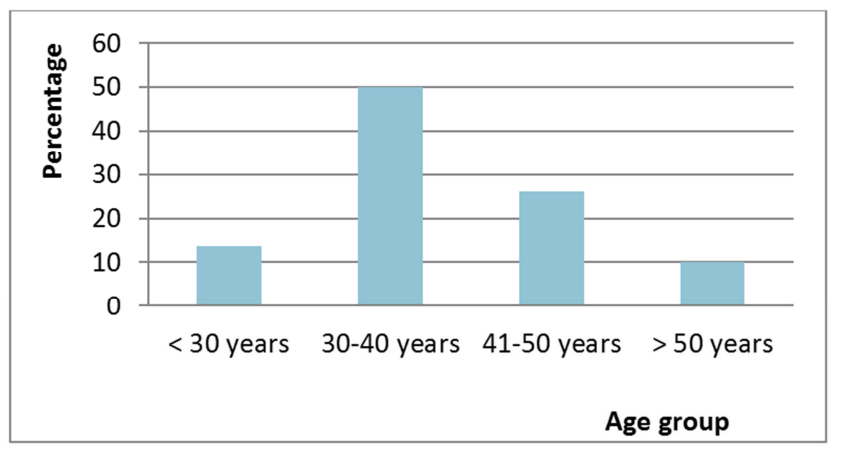

Figure 1. Frequency of cases studied by age group.

\subsection{Distribution of the Cases Studied According to the Method of Sampling}

\subsubsection{Distribution of Cases Studied According to Colposcopy}

Of the 264 cases studied, colposcopy showed that about half of the cases $(43.2 \%)$ had a normal cervix and $35.6 \%$ an atypical stage 1 (TA1) transformation. Rates of condyloma and stage 2 atypical transformation (TA2) were relatively low (approximately $5.7 \%$ and $2.6 \%$, respectively). Finally, $12.9 \%$ of our population had invasive squamous cell carcinoma (Table 2, Figure 2).

Table 2. Comparison of the results of cyto-histology and colposcopy of the cases studied.

\begin{tabular}{|c|c|c|c|c|c|c|}
\hline \multirow{2}{*}{$\begin{array}{l}\text { Clinical stage } \\
\text { Normal cervix }\end{array}$} & \multirow{2}{*}{$\begin{array}{l}\text { Diagnosis } \\
\text { Normal cervix }\end{array}$} & \multicolumn{2}{|c|}{ Cyto-histology n \% } & \multicolumn{2}{|c|}{ Colposcopy n \% } & \multirow{2}{*}{$\frac{\mathbf{p}}{\mathrm{NS}^{*}}$} \\
\hline & & 100 & 37.9 & 114 & 43.2 & \\
\hline \multirow[t]{2}{*}{ Minor lesion } & Inflammatory cervix & 23 & 8.7 & l & / & \\
\hline & Condyloma & 13 & 4.9 & 15 & 5.7 & NS \\
\hline low grade dysplasia & CIN1/TA1* & 80 & 30.3 & 94 & 35.6 & NS \\
\hline High grade dysplasia, CIS* & (CIN2/CIN3)/TA2* & 14 & 5.3 & 07 & 2.6 & NS \\
\hline invasive cancer & invasive squamous cell cancer & 34 & 12.9 & 34 & 12.9 & NS \\
\hline Total & & 264 & 100 & 264 & 100 & \\
\hline
\end{tabular}

*TA1, TA2: stage 1, stage 2, atypical transformation. * CIN2 / CIN3: stage 2 / stage 3 cervical intraepithelial neoplasia. CIN1 / TA1 *: CIN1 in cyto-histology corresponds to TA1 in colposcopy. (CIN2 / CIN3) / TA2 *: CIN2 / CIN3 in cyto-histology correspond to TA2 in colposcopy. CIS: carcinoma in situ. NS: not significant (chi-square test). 


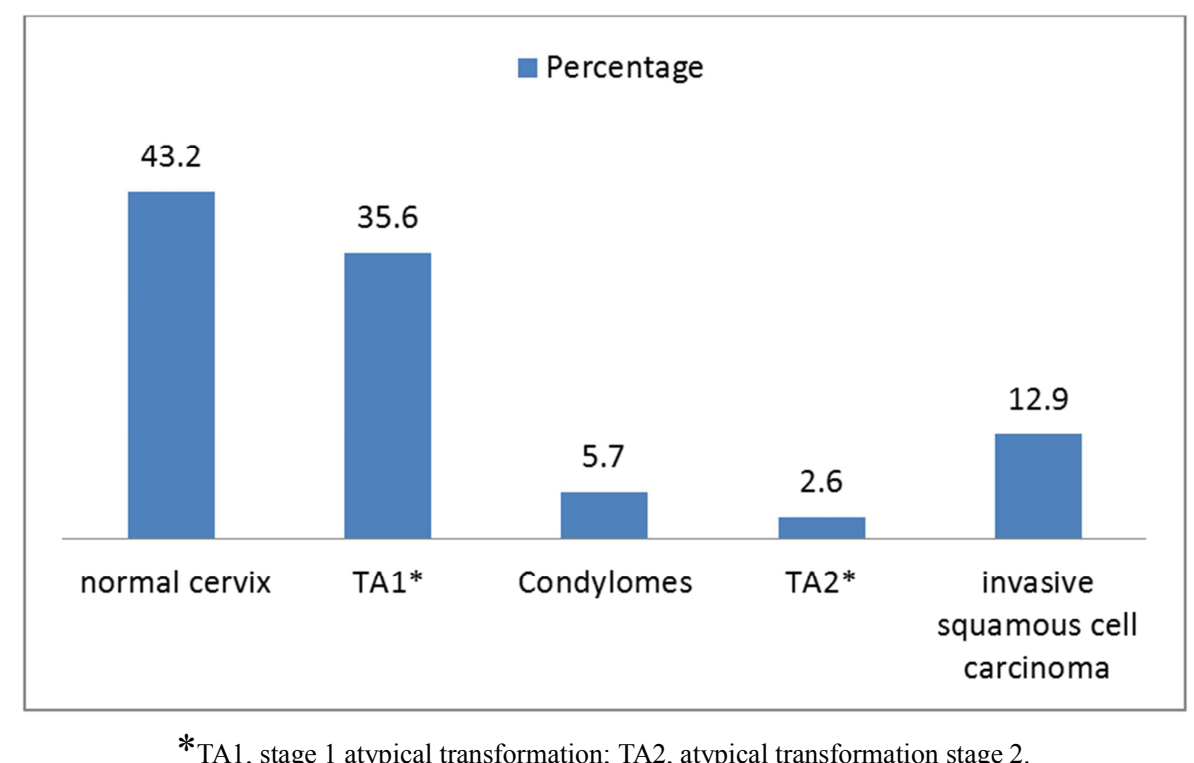

Figure 2. Frequency of cases studied according to colposcopy.

\subsubsection{Cytohistologic Case Distribution}

Among the 264 cases studied, $37.9 \%$ had a normal cervix, $30.3 \%$ had a low-grade cervical lesion or CIN I (stage I cervical intraepithelial neoplasia).) and only $5.3 \%$ had a highgrade CIN2 / CIN3 cervical lesion (stage 2 and 3 cervical intraepithelial neoplasia). Inflammatory lesions and condylomas were $8.7 \%$ and $4.9 \%$ respectively. Again, cytology revealed $12.9 \%$ invasive squamous cell carcinoma (Table 2, Figure 3).

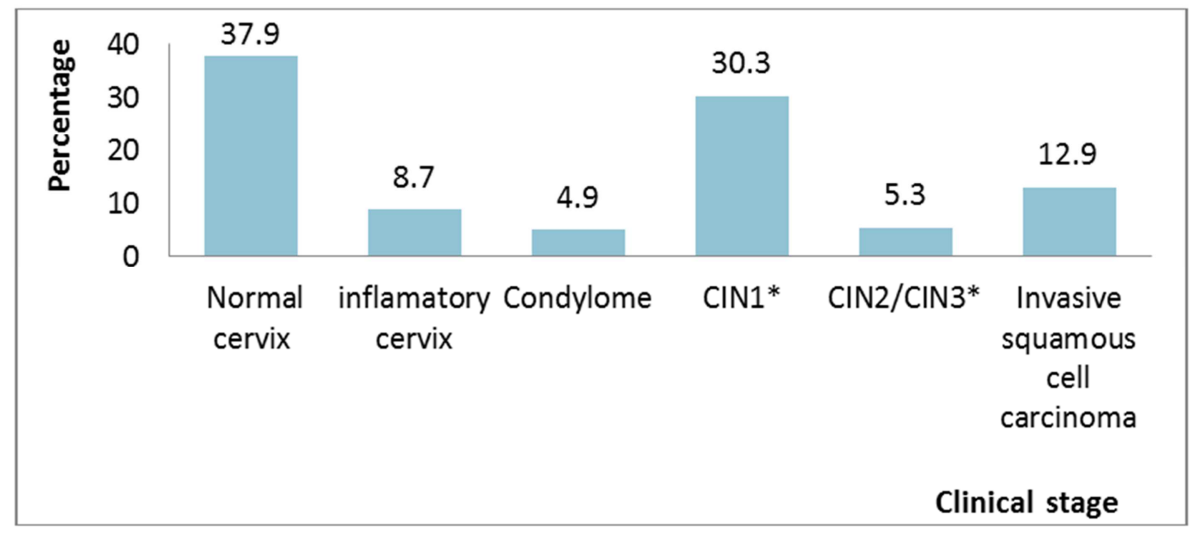

* CIN1, CIN2, CIN3, cervical intraepithelial neoplasia 1, 2, 3 .

Figure 3. Distribution of the cases studied according to cyto-histology.

\subsubsection{Comparison of the Results of Colposcopy and Cyto-histology}

Of the 264 women studied, $37.9 \%$ and $43.2 \%$ of women had a normal cervix, according to the results of cytohistology and colposcopy, respectively. For low grade lesions, $30.3 \%$ of women had CIN1 lesions versus $35.6 \%$ TA1. As for the high-grade lesions, $5.3 \%$ of CIN 2 / CIN 3 by cyto-histology versus $2.6 \%$ of TA2 by colposcopy were obtained. $12.9 \%$ of invasive squamous cell carcinomas were diagnosed by both cyto-histology and colposcopy. However, there were no significant differences between cytohistological diagnosis and colposcopic diagnosis regardless of stage of cervical injury (Table 2).

\subsection{Highlighting and Prevalence of HPV by Capture Hybridization 2 and PCR}

\subsubsection{HPV Detection by Hybridization Capture 2 (Digene HPV Hybrid Capture 2) (HC2)}

\section{(i) According to the Cyto-histological Diagnosis}

The study involved 236 cervical specimens (scraping or biopsies). The detection of HPV is presented according to the grade of the lesion of the cervix as determined by cytohistology. Table 1 shows the results obtained by HC2 on all the samples that have been subjected to cyto-histological examination. HPV-BR (low risk virus) was poorly found in minor and low-grade lesions. Their prevalence decreased as 
the lesion worsened. The opposite is observed for oncogenic viruses (HPV-HR). High-grade lesions were home to more HPV-HR (including 16 and 18). Indeed, the prevalence of HPV-HR (high risk virus) reached $100 \%$ in high-grade lesions and was $83.3 \%$ in invasive squamous cell cancers. It should be noted that HPV-HR was found in $15.4 \%$ of lowgrade lesions and $34.6 \%$ of minor lesions, respectively. Normal cervices had $19.3 \%$ HPV-HR. Finally, about $26 \%$ of apparently healthy women (normal cervix) had high or low risk viruses (Table 3 ).

Table 3. Detection of HPV by Hybrid Capture 2 in the cases studied.

\begin{tabular}{|c|c|c|c|c|c|c|}
\hline \multirow{2}{*}{ Number } & \multirow{2}{*}{ HPV (HC2) } & \multicolumn{5}{|c|}{ Cyto-histological test } \\
\hline & & Normal cervix & Minor lesions & CIN1 $^{*}$ & CIN2/CIN3* & Invasive squamous cell cancer \\
\hline \multirow{4}{*}{236} & / & $\mathrm{n}=88$ & $\mathrm{n}=26$ & $\mathrm{n}=78$ & $\mathrm{n}=14$ & $\mathrm{n}=30$ \\
\hline & Negative (\%) & $65(73.9)$ & $11(42.3)$ & $60(76.9)$ & $00(0)$ & $03(10.0)$ \\
\hline & HPV-BR $(\%)$ & $06(6.8)$ & $06(23.1)$ & $06(7.7)$ & $00(0)$ & $02(6.7)$ \\
\hline & HPV-HR (\%) & $17(19.3)$ & $09(34.6)$ & $12(15.4)$ & $14(100)$ & $25(83.3)$ \\
\hline
\end{tabular}

\subsubsection{Detection of HPV by Digene Sharp System-PCR}

\section{(i) According to the Cyto-histological Diagnosis}

Compared to Table 3 making use of the capture hybridization technique 2 , the results of Table 4 obtained by PCR show that the HPV-HR levels detected are higher in each lesion of the cervix including in normal cervix compared to those detected with the capture hybridization technique 2.
It should be emphasized that for all of our PCR and HC2 viral detection (HPV-HR) results, there is a correlation between the severity of the cervical lesion and the test positivity rate for a test HPV type oncogene. It should also be noted that higher HPV-HR levels were detected in normal cervix compared to those detected in minor and low-grade lesions. It is also noted that the prevalence was higher for high-risk HPV than for low-risk HPV (Table 4).

Table 4. Detection of HPV by PCR in the cases studied.

\begin{tabular}{|c|c|c|c|c|c|c|}
\hline \multirow{2}{*}{ Number } & \multirow{2}{*}{ HPV (PCR) } & \multicolumn{5}{|c|}{ Cyto-histological test } \\
\hline & & Normal cervix & Minor lesions & CIN1 $^{*}$ & CIN2/CIN3* & Invasive squamous cell cancer \\
\hline \multirow{4}{*}{260} & I & $\mathrm{n}=98$ & $\mathrm{n}=36$ & $\mathrm{n}=78$ & $\mathrm{n}=14$ & $\mathrm{n}=34$ \\
\hline & Negative (\%) & $42(42.8)$ & $06(16.7)$ & $30(38.5)$ & $00(0)$ & $00(0)$ \\
\hline & HPV-BR (\%) & $00(0)$ & $06(16.7)$ & $10(12.8)$ & $00(0)$ & $4(11.8)$ \\
\hline & HPV-HR (\%) & $56(57.1)$ & $24(66.7)$ & $38(48.7)$ & $14(100)$ & $30(88.2)$ \\
\hline
\end{tabular}

The search for HPV-HR by PCR and HC2 found that these viruses were associated with high-grade lesions (CIN2 / CIN3) at $100 \%$ but at $88.2 \%$ by PCR and $83.3 \%$ by HC2 (p = 0.83 , not significant difference) to invasive squamous cell cancer. For normal, minor, and low-grade lesions, prevalence rates of HPV-HR infection were significantly higher ( $p$ $<0.0001, \mathrm{p}<0.02, \mathrm{p}<0.0001$, respectively) in favor of PCR test compared to the HC2 test (Table 5).

Table 5. Summary and comparative table of prevalences of HPV-HR infection detected by PCR and Hybrid capture 2 in the cases studied.

\begin{tabular}{|c|c|c|c|c|c|c|}
\hline \multirow{2}{*}{$\begin{array}{l}\text { Clinical } \\
\text { diagnosis }\end{array}$} & \multirow[b]{2}{*}{ HPV Test } & \multicolumn{5}{|l|}{ HPV-HR (\%) } \\
\hline & & Normal cervix & Minor lesions & Low grade lesions CIN1 & $\begin{array}{l}\text { High grade lesions } \\
\text { CIN2/CIN3 }\end{array}$ & $\begin{array}{l}\text { Invasive squamous } \\
\text { cell cancer }\end{array}$ \\
\hline \multirow{3}{*}{ Cyto-histology } & PCR & $56(57.1)$ & $24(66.7)$ & $38(48.7)$ & $14(100)$ & $30(88.2)$ \\
\hline & $\mathrm{HC} 2$ & $17(19.3)$ & 09 (34.6) & $12(15.4)$ & $14(100)$ & $25(83.3)$ \\
\hline & $\mathrm{P}$ & $<0.0001$ & 0.02 & $<0.0001$ & $\mathrm{NS}^{*}$ & 0.83 (NS) \\
\hline
\end{tabular}

\subsection{HPV Test Performance at CIN2 + / CIN3 + Level}

Parameters of HPV testing by HC2 and PCR are estimated by calculating the various parameters between cases of high grade CIN2 + / CIN3 + (gold standard) lesions that include severe dysplasia and carcinoma in situ compared with normal cervix (Table 6).

No significant difference in sensitivity was noted between PCR (91.7\%) and HC2 (88.6\%). The specificity was significantly in favor of the HPV test by $\mathrm{HC} 2$ compared to that obtained by PCR $(80.2 \%$ versus $44.3 \%)$. The VPP for the HPV PCR test $(27.2 \%)$ was significantly different ( $<0.0001)$ from the VPP for the HPV HC2 test $(50.6 \%)$. The
VPNs were not significantly different between PCR and HC2 (95.9\% versus $96.9 \%, \mathrm{p}<0.70)$. This parameter highlights the etiological role of HPV-HR in the development of high-grade lesions and cervical cancer in the studied population. The Youden index, which provides information on the effectiveness of the test, shows the effectiveness of the HCV HPV test, whose values are close to $1(0.7)$ compared to the HPV PCR test (0.4). The Q coefficient of Yule, which measures the intensity of the binding between the two variables (disease / sign), shows a strong binding with the PCR (0.8) even stronger with HC2 (0.9). This coefficient clearly shows the causal role of HPV-HR in the development of high-grade lesions and cervical cancer (Table 6). 
Table 6. Summary and comparative table of the performance parameters of the HPV test at CIN2 + / CIN3 + level by PCR and Hybrid capture 2 (HC2).

\begin{tabular}{llllllll}
\hline \multirow{2}{*}{ clinical Diagnosis } & \multirow{2}{*}{ HPV Test } & \multicolumn{2}{l}{ Performance parameters of the HPV test } & & \\
\cline { 3 - 7 } & & Sensitivity (\%) & Specificity (\%) & VPP $^{*} \mathbf{( \% )}$ & VPN $^{*}(\%)$ & Youden index & Q coefficient of Yule \\
\hline \multirow{2}{*}{ Cyto-histology } & PCR & 91.7 & 44.3 & 27.2 & 95.9 & 0.4 & 0.8 \\
& HC2 & 88.6 & 80.2 & 50.6 & 96.9 & 0.7 & 0.9 \\
& P & $0.29(\mathrm{NS})$ & $<0.0001$ & $<0.0001$ & $0.70(\mathrm{NS})$ & & \\
\hline
\end{tabular}

* VPP: positive predictive value; VPN: negative predictive value.

\section{Discussion}

Among the 264 cases studied, the distribution by age group revealed that $50 \%$ of women presenting in a gynecological consultation were between 30 and 40 years old, which is the peak of age in this sample. The age at consultation fell sharply by about half for age groups 41-50 (26.1\%) and reached only $10.2 \%$ for women over 50 years of age. the results obtained are largely in agreement with the data established in relation to age. Indeed, women under 45 are the most affected because they are usually women in sexual activity. On the other hand, if one considers the variation of the risk to which a woman is exposed according to her age (called longitudinal effect of the age), one observes that the risk of incidence increases with the age until 40 years and decreases then [10].

According to the results obtained, only $13.6 \%$ of women consult before age 30 , probably because of cultural and traditional factors that do not encourage the precocity of sexual intercourse as is the case in Western countries. The early onset of sexual intercourse is a major risk factor for cervical cancer [11]. Moreover, in most cases, especially in women under 30, HPV infections are transient and are accompanied by the disappearance of the cytological and histological abnormalities they may have induced [12-15]. It is also accepted that 25 to $40 \%$ of women, aged 15 to 25 , carry HPV-HR without necessarily having underlying lesions [16]. The comparison of the results of the diagnosis of the different cervical lesions by cyto-histology and colposcopy revealed no significant difference for the different grades of cervical lesions. Better still, the diagnosis of an invasive squamous cell cancer by the two techniques in question was established at identical rates, $12.9 \%$ in this case. But if the comparison of the results of cyto-histology and colposcopy, according to this study, seems to indicate a good correlation, this does not exclude the reality in medical practice that colposcopy is the essential examination to explore the cervix of the uterus when the smears are abnormal. It makes it possible to pinpoint the abnormal areas, to judge their severity, to map them to locate them and finally to perform a biopsy to obtain a diagnosis of certainty. The major disadvantage of colposcopy is intra- and inter-observer variability. However, it remains a reference technique because it is highly sensitive for recognizing high-grade lesions, although its specificity remains low (less than 50\%) [17].

The results for viral screening (HPV-HR) by PCR and HC2 showed a correlation between the severity of the cervical lesion and the test positivity rate for an oncogenic
HPV. Indeed, it is shown that the higher the cytological abnormality, the higher the probability of finding viral DNA. At the same time, the higher the cytological abnormality, the higher the probability of histological lesions in the cervix $[18,19]$. The results obtained showed that the rate of normal cervical HPV-HR infected was $19.3 \%$. About $12 \%$ of women with normal cervical smears show cervical HPV carriage detected by molecular biology, with women in sub-Saharan Africa showing the highest prevalence (24\%) compared to women from Eastern Europe (21\%) or Latin America (16\%) [20]. On the other hand, higher HPV-HR levels detected in normal cervix compared to minor and low-grade lesions seem to be explained by the phenomenon of viral clearance (elimination of viral infection). Indeed, many studies have shown that in most cases, especially in women under 30 , HPV infections are transient [12-15]. Viral clearance of HPV is quite fast and frequent, on average $70 \%$ of infections disappear in 12 months and $90 \%$ in 24 months [21-23]. The search for HPV-HR by PCR and HC2 found that these viruses are associated with high-grade lesions (CIN2 / CIN3) at $100 \%$. Similar results were also reported [24] where all cases of high-grade lesions $(100 \%)$ were associated with HPV-HR. In invasive squamous cell cancer, this association with HPV-HR is $88.2 \%$ by PCR and $83.3 \%$ by HC2 (p = 0.8 ). These results are comparable to those found in Tunisia $(87.5 \%)$ [25] as well as at the international level where a meta-analysis [26] carried out on 85 studies gives an average HPV-HR prevalence of $86.4 \%(84.8$ to $89.5 \%)$ in cervical cancers. In Morocco and Tunisia, this prevalence is only $63 \%$ and $66.7 \%$ respectively when it is restricted to HPV-HR 16 and 18 [27, 25]. For normal, minor, and low-grade cervical lesions, prevalence rates of HPV-HR infection were significantly elevated in favor of the PCR test compared to the HC2 test. However, these rates are much lower when compared to prevalence rates of HPV-HR in high-grade lesions and invasive cancer.

The comparison of PCR and HC2 techniques in terms of performance in the detection and typing of HPV was based on sensitivity, specificity, VPP, VPN, Youden index and Yule $\mathrm{Q}$ coefficient parameters. Both techniques seem to have the same sensitivity to detect HPV-HR. However, HC2 seems more suitable to be integrated into less equipped laboratories because of its simplicity and ease of execution. Especially since the sensitivity of the smear test in first-line screening of cervical lesions does not exceed 58\% [28] and 53\% according to [29] and [30] in its meta-analysis on the countries of Europe and North America. It is only 51\% according to other works [31]. Therefore, the lack of sensitivity of the smear test causes the problem of false 
negatives and thus allows the active tumor process to develop.

According to the results obtained, the HCV HPV test is significantly more specific than that obtained by PCR. The specificity is nevertheless lower with the HC2 test compared to cervical-uterine Pap smear (FCU) [38, 32, 24]. Other molecular test parameters that highlight the etiologic role of HPV-HR in cervical oncogenesis and reinforce the specificity parameter, namely, VPP, VPN, Youden's index and Yule's Q coefficient are in favor of the performance of the HC2 test for HPV-HR research compared to the PCR technique. The HC2 test has a near $100 \%$ VPN in European studies, as is the case in our results (97\%), which means that a negative woman has an extremely low risk of having high lesions. grade within three to five years of the examination [33]. Thus, according to the results obtained, all these parameters make the capture hybridization technique 2 the best choice as a molecular test for the detection and identification of HPV-HR and best suited in unstructured laboratories. This test has a very good clinical significance and the technique is fast, reproducible and applicable to large series $[34,35,39]$. In fact, the significant protection attributed to this screening tool for CIN3 and invasive cancer is one of the powerful arguments for its implementation [36]. However, and to overcome its low specificity compared to the FCU, it can be recommended in the detection of HPV-HR in first intention in association with Pap smear. In fact, the screening associating the HPV test and cytology has a negative prognostic value (NPV) of nearly $100 \%$. Numerous large studies have confirmed these findings in women over 30 years of age [33, 32, 37]. This strategy is currently recommended in the USA. It is being tested in some European regions [26]. This combination gives the hope of increasing the screening interval from 1-3 years to 3-5 years [37].

\section{Conclusion}

The results obtained on the prevalence of HPV-HR are in agreement with the data from the literature.

The demonstration of the association of $100 \%$ high-grade cervical lesions with HPV-HR diagnosed by HC2 according to the results obtained demonstrates the effectiveness of this molecular test compared to PCR and justifies its use as an alternative or in complement to conventional screening methods, Pap smear (FCU) in this case in the diagnosis of precancerous lesions of the uterus. From this point of view, this work related to molecular diagnosis could constitute a basis for the implementation of a prevention program based on the early molecular diagnosis of HPV-HR in normal cervix and the follow-up of this infection in cervical lesions of low and high grade.

The high prevalence rates of HPV-HR in the studied population, which are comparable to the Maghreb and European data, as well as the association rates of these oncogenic viruses to $100 \%$ of high-grade cervical lesions, should encourage the health authorities in Algeria to adopt a prevention policy focusing on the introduction of prophylactic anti-HPV vaccination in young girls.

\section{References}

[1] Ferlay J, Soerjomataram I, Dikshit R, et al. Cancer incidence and mortality worldwide: sources, methods and major patterns in GLOBOCAN 2012. Int J Cancer 2015; 136: E359-386.

[2] Ho G, Burk R, Klein S, Kadish A, Chang C, Palan P, et al. Persistent genital human papillomavirus infection as a risk factor for persistent cervical dysplasia. J Natl Cancer Inst 87 (1995), 1365-71.

[3] Koshiol J, Lindsay L, Pimenta J, Poole C, Jenkins D, and Smith J. Persistent human papillomavirus infection and cervical neoplasia: a systematic review and metaanalysis. Am J Epidemiol 168 (2008), 123-37.

[4] Sadouki N, Boudriche A, Khenchouche A, Benyacoub D, Djennaoui T, Boudriche H, et al. Détection des papillomavirus à haut risque dans les lésions précancéreuses du col en Algérie; état des lieux et perspective. Arch Inst Pasteur Alger T 67 (2010), 53-82.

[5] Brink AA, Snijders P CJ, Berkhof J, Verheijen RH. HPV testing in cervical screening. Best Pract Res Clin Obstet Gynécol 2006; 20: 253-66.

[6] Cuzick J, Mayrand MH, Ronco G, Snijders P, Wardle J. Chapter 10: New dimensions in cervical cancer screening. Vaccine 2006; 24 Suppl 3: S3/90-7.

[7] Wells M, Ostor AG, Crum CP, Franceschi S, Tommasino M, Nesland JM, et al. Tumors' of the breast end female genital organs. Lyon: IARC Press, 2003.

[8] Sankaranarayanan R, et al (2009) HPV Screening for Cervical Cancer in Rural India. N. Engl. J. Med. 360, 1385-1394.

[9] Snijders PJ, van den Brule AJ, Schrijnemakers HF, Snow G, Meijer CJ, Walboomers JM. The use of general primers in the polymerase chain reaction permits the detection of a broad spectrum of human papillomavirus genotypes. J Gen Virol 1990; 71: 173-81.

[10] Fédération des Gynécologues et Obstétriciens de Langue Française. Conférence de consensus sur le dépistage du cancer $\mathrm{du}$ col utérin, Lille 5-6-7-8 septembre 1990. Recommandations. J Gynécol Obstét Biol Reprod 1990;19:1

[11] Haute Autorité de Santé (HAS) - Dépistage et prévention du cancer du col de l'utérus Actualisation du référentiel de pratiques de l'examen périodique de santé (EPS) Juin 2013Referentiel-KC Uterus juin 2013 - $\mathrm{N}^{\circ}$ ISBN: 978-2-11128544-6

[12] Monsonego J. Cervical cancer prevention: the impact of HPV vaccination. Gynecol Obstet Fertil 2006 Mar; 34(3):189-201.

[13] Moscicki AB, Schiffman M, Kjaer S, Villa LL. Chapter 5: Updating the natural history of HPV and anogénitale cancer. Vaccine 2006 Aug 21; 24 Suppl 3:S42-S51.

[14] Ostor AG. Natural history of cervical intraepithelial neoplasia: a critical review. Int J Gynecol Pathol 1993 Apr; 12(2):18692.

[15] Schlecht NF, Platt RW, Duarte-Franco E, Costa MC, Sobrinho JP, Prado JC, et al. Human papillomavirus infection and time to progression and regression of cervical intraepithelial neoplasia. J Natl Cancer Inst 2003 Sep 3; 95 (17):1336-43. 
[16] Halfon P, Lindemann M, Raimondo A, Ravet S, Camus C, Khiri H, Pénaranda G, Sideri M, and Sandri M. HPV genotype distribution according to severity of cervical neoplasia using the Digene HPV genotyping LQ test. Arch Virol 158 (2013), $1143-9$.

[17] Mergui J, Polena V, David-Montefiore E, and Uzan S. Recommandations pour la surveillance des patientes traitées pour des lésions de haut grade du col utérin. J Gynecol Obstet Biol Reprod (Paris) 37 (2008), S121-30.

[18] Beby-Defaux A, Bourgoin A, Ragot S, Battandier D, Lemasson JM, Renaud $\mathrm{O}$, et al. Human papillomavirus infection of the cervix uteri in women attending a Health Examination Center of the French social security. J Med Virol 2004 Jun; 73 (2):262-8.

[19] Dalstein V, Riethmuller D, Sautiere JL, Pretet JL, Kantelip B, Schaal JP, et al. Detection of cervical precancer and cancer in a hospital population; benefits of testing for human papillomavirus. Eur J Cancer 2004 May; 40(8):1225-32.

[20] Bruni L, Diaz M, Castellsague' X, et al. Cervical human papillomavirus prevalence in 5 continents: meta-analysis of 1 million women with normal cytological findings. J Infect Dis 2010; 202: 1789-99.

[21] Baseman JG, Koutsky LA. The epidemiology of human papillomavirus infections. J Clin Virol 2005 Mar; 32 Suppl 1:S16-S24.

[22] Riethmuller D, Schaal JP, Mougin C. [Epidemiology and natural history of genital infection by human papillomavirus]. Gynecol Obstet Fertil 2002 Feb; 30(2):139-46.

[23] Ho GY, Bierman R, Beardsley L, Chang CJ, Burk RD. Natural history of cervicovaginal papillomavirus infection in young women. N Engl J Med 1998 Feb 12; 338(7):423-8.

[24] Levert M, Clavel C, Graesslin O, Masure, M, Birembaut P, Quereux C, and Gabriel R. Typage des Papillomavirus humains dans les frottis cervicaux de routine. Résultats sur une série de 3778 patientes. Gynécol Obstét et Fertil 28 (2000), 722-8.

[25] Nahiba Missaoui, Sihem Hmissa, Amel Trabelsi, Mohamed Tahar acoubi, Amel Nouira, Lucien Frappart, et al. Prévalence des infections à papillomavirus (HPV) dans les lésions précancéreuses et cancéreuses du col utérin en Tunisie. Ann Biol Clin 2010; 68 (3): 297-303.

[26] ANAES. Evaluation de l'intérêt de la recherché des papillomavirus humains (HPV) dans le dépistage des lésions précancéreuses et cancéreuses du col de l'utérus. Tech. rep., Agence nationale d'accréditation et d'évaluation en santé, France, 2004.

[27] Elgnaoui N, Gazzaz B, Khyati M, Benchakroun N, Benidder A, Hassar M, et al. Rôle des papillomavirus humains (HPV) dans le cancer du col utérin au Maroc et facteurs associés. Journal Biologie et Santé de Casablanca (JBS 2004); Décembre 2004: 15-16
[28] Fahey M, Irwig L, and Macaskill P. Meta-analysis of Pap test accuracy. Am J Epidemiol 141 (1995), 680-9.

[29] Koliopoulos G, Arbyn M, Martin-Hirsch P, Kyrgiou M, Prendiville W, and Praskevaidis E. Diagnostic accuracy of human papillomavirus testing in primary cervical screening. A systematic review and meta-analysis of non-randomized study. Gynecol Oncol 104 (2007), 232-46.

[30] Cuzick J, Clavel C, Petry K, Meijer C, Hoyer H, Ratnam S, et al. Overview of the European and North American studies on HPV testing in primary cervical cancer screening. Int $\mathbf{J}$ Cancer 119 (2006), 1095-101.

[31] Jeronimo J, Bansil P, Lim J, Peck R, Paul P, Amador J, et al. A multicountry evaluation of care HPV testing, visual inspection with acetic acid, and Papanicolaou testing for the detection of cervical cancer. Int J Gynecol Cancer 24 (2014), 576-85.

[32] Cuzick J, Arbyn M, Sankararayanan R, Tsu U, Ronco G, Mayrand M, et al. Overview of human papillomavirus based and other novel option for cervical cancer screening in developed and developing countries. Vaccine 265 (2008), K29-K41.

[33] Monsonego J. Traité des infections et pathologies génitales à papillomavirus. Springer-Verlag Paris, France, 2007.

[34] Clavel C, Masure M, Bory JP, et al. Human papillomavirus testing in primary screening for the detection of high-grade cervical lesions: a study of 7932 women. Br J Cancer 2001; 84: 1616-23.

[35] Bory JP, Cucherousset J, Lorenzato M, et al. Recurrent human papillomavirus infection detected with the hybrid capture II assay selects women with normal cervical smears at risk for developing high grade cervical lesions: a longitudinal study of 3,091 women. Int J Cancer 2002; 102: 519-25.

[36] Monsonego J. Test HPV et prévention du cancer du col utérin: pratiques et tendances actuelles. Ann Biol Clin 2013; 71(spécial 1): 27-32 doi:10. 1684/abc. 2013. 0907

[37] Bhatla N, and Moda N. The clinical utility of HPV DNA testing in cervical cancer screening strategies. Indian J Med Res 130 (2009), 261-5.

[38] INESSS (Institut national d'excellence en santé et en services sociaux. Comparaison des stratégies de dépistage du cancer du col de l'utérus avec le test de détection des virus de papillome humain (test VPH) ou la cytologie gynécologique (test PAP). État des connaissances rédigé par Julie Lessard, Khalil Moqadem, Patricia Goggin et Marie-Hélène Mayrand. Québec, Qc: INESSS; 2017. 58p.

[39] Zhao X, et al. The performance of human papillomavirus DNA detection with type 16/18 genotyping by hybrid capture in primary test of cervical cancer screening: a cross-sectional study in 10,669 Chinese women, Clinical Microbiology and Infection (2018), https://doi.org/10.1016/j.cmi.2018.02.027 